\title{
Membrane Assisted Simultaneous Extraction and Derivatization with Triphenylphosphine of Elemental Sulfur in Arabian Crude Samples by Gas Chromatography/Mass Spectrometry
}

\author{
Ibrahim Al-Zahrani, ${ }^{1}$ Munzir H. Aneel Mohammed, ${ }^{1}$ Chanbasha Basheer, ${ }^{1,2}$ \\ Mohammad Nahid Siddiqui, ${ }^{1,2}$ and Abdulrahman Al-Arfaj ${ }^{1}$ \\ ${ }^{1}$ Department of Chemistry, King Fahd University of Petroleum and Minerals, P.O. Box 1509, Dhahran 31261, Saudi Arabia \\ ${ }^{2}$ Center of Excellence in Nanotechnology, King Fahd University of Petroleum and Minerals, Dhahran 31261, Saudi Arabia
}

Correspondence should be addressed to Chanbasha Basheer; cbasheer@kfupm.edu.sa

Received 5 October 2014; Revised 8 December 2014; Accepted 9 December 2014

Academic Editor: José Morillo Aguado

\begin{abstract}
Copyright ( 2015 Ibrahim Al-Zahrani et al. This is an open access article distributed under the Creative Commons Attribution License, which permits unrestricted use, distribution, and reproduction in any medium, provided the original work is properly cited.

Determination of trace level elemental sulfur from crude oil samples is a tedious task. Recently, several gas chromatographic methods were reported in which selective triphenylphosphine derivatization of sulfur was used to form triphenylphosphine sulfide. Direct quantitation of elemental sulfur from crude oil requires an efficient sample preparation method. This paper describes how simultaneous extraction derivatization of elemental sulfur was performed for the first time using porous hollow fiber membrane. A thick ( $0.25 \mathrm{um}$ pore size; $1550 \mu \mathrm{m}$ wall thickness; and $5500 \mu \mathrm{m}$ inner diameter) hollow fiber membrane filled with triphenylphosphine (dissolved N-methylpyrrolidone) is used as a solvent bar. The solvent bar is tumbled freely in the crude oil sample; the elemental sulfur was extracted and derivatized. Finally, the derivatized sulfur was analyzed by gas chromatography/mass spectrometry. Various experimental conditions of solvent bar microextraction (SBME) were optimized to achieve higher extraction. The linear range was established between 1 and $50 \mu \mathrm{g} / \mathrm{mL}$, while a squared regression coefficient was found to be $0.9959 \mu \mathrm{g} / \mathrm{mL}$. Relative standard deviation (RSD) was below $10 \%$. Relative recoveries were calculated for SBME in crude oil samples and were in the range between $98.2 \%$ and $101.2 \%$.
\end{abstract}

\section{Introduction}

Sulfur compounds are naturally present in crude oil, and removal of sulfur compounds is necessary to improve the performance of the distillates. A number of procedures are reported for the elimination of sulfur compounds, which includes hydrodesulphurization (HDS) [1], oxidative desulfurization, absorption [2], and solvent assisted desulfurization [3]. None of these methods are able to remove sulfur compounds completely. Trace amounts of benzothiophenes (BTs), dibenzothiophenes (DBTs), and elemental sulfur are often detected as distillate fractions of crude oil $[1,3]$. Interestingly, elemental sulfur was produced during the HDS process of gasoline, and once the elemental sulfur is formed in the process, it is difficult to remove. Interestingly, depending on the temperature, elemental sulfur changes its structure (from $\mathrm{S}_{2}, \mathrm{~S}_{6}$, and $\mathrm{S}_{7}$ and then finally changes to $\mathrm{S}_{8}$ ) $[4,5]$. This creates further challenges for the analyses of elemental sulfur, and most of the methods are reporting total sulfur concentrations, which includes organic and elemental sulfur from gasoline samples. A number of the following studies were focused on the determination of elemental sulfur.

One of the earliest methods developed to determine elemental sulfur is based on calorimetry in this technique; the extracted elemental sulfur is allowed to react with cyanide ions $\left(\mathrm{CN}^{-}\right)$to form thiocyanate ions $\left(\mathrm{SCN}^{-}\right)$quantitatively. The thiocyanate ions subsequently react with $\mathrm{Fe}^{3+}$ to form the red $\left[\mathrm{Fe}(\mathrm{SCN})_{4}\right]^{-}$complex, which is determined by calorimetry $[6,7]$. The instability of the complex leads to poor precision in analysis [8]. To overcome these difficulties during 
the $80 \mathrm{~s}$, the polarography method was introduced in which $[9,10]$ elemental sulfur is converted to thiosulfate by the addition of an excess of sodium sulfite. To improve the sensitivity in petrochemical applications, Serafim and Stradiotto (2008) described a voltammetric technique with the use of mercury film electrode. Unfortunately, most voltammetry methods required mercury electrodes, but the toxicity of mercury limits the usage of the mercury electrodes in the analytical practice and excludes them from the out-of-laboratory applications [11]. In size exclusion chromatography (SEC), the sulfur peak has served as the flow-rate marker; based on this concept, Barman (1996) [12] first demonstrated the use of SEC for quantitative measurement of sulfur from petroleum applications.

Recent reports of chromatographic methods involve derivatization with triphenylphosphine prior to gas chromatography-mass spectrometry (GC-MS) [13], GC-electron caption detector [14], and high performance liquid chromatography analyses [15]. To avoid derivatization, selective detectors such as GC-pulsed flame photometric detector and GC-sulfur chemiluminescence detector have been reported $[16,17]$. Compared with other methods, chromatographic methods are quick, simple, and accurate for elemental sulfur analyses [18]. In most chromatography applications, petroleum samples are diluted and directly analyzed in the instruments, but the dilution method for complex crude oil analyses builds up matrices in the injection port or on the separation column, which leads to instrument failures and errors in quantitation.

In this paper, a single step solvent bar microextraction (SBME) is reported for simultaneous extraction, derivatization, and preconcentration method for elemental sulfur from direct crude oil samples. The SBME is a fast, simple, and inexpensive extraction procedure. To enhance the sample cleanup, we used a thick porous polypropylene membrane. The porous thick polypropylene membrane acts as a filter and eliminates most of the interfering materials, producing a clean extract suitable for the direct instrumental analyses. To the best of our knowledge, for the first time, the thick porous membrane and SBME were used for the determination of the elemental sulfur in the complex matrices.

\section{Experimental Section}

2.1. Materials. High purity elemental sulfur, triphenylphosphine (TPP), and triphenylphosphine sulfide (TPS) were obtained from Sigma-Aldrich (St. Louis, MO, USA). HPLCgrade organic solvents (acetone, furfural, furfuryl alcohol, and N-methylpyrrolidone) were purchased from SigmaAldrich to extract the sulfur compounds. A thin-walled polypropylene hollow fiber membrane, Q3/2 Accurel $(600 \mu \mathrm{m}$ inner diameter [ID], $200 \mu \mathrm{m}$ wall thickness, and $0.2 \mu \mathrm{m}$ wall pore size), and thick-walled polypropylene hollow fiber membrane, V8/2 HF (nominal pore size is $0.2 \mu \mathrm{m}$; wall thickness is $1550 \mu \mathrm{m}$; and the ID is $5500 \mu \mathrm{m}$ ), were purchased from Membrana (Wuppertal, Germany). Diesel and Arabian crude oils (light, medium, and heavy) were procured from Saudi Aramco before desulfurization. Spiked standards of elemental sulfur were prepared using an ultralow sulfur diesel after being treated with hydrodesulfurization at Saudi Aramco.

2.2. Sample Characterization. The API gravity and density of the crude oil range from 27 to 33 and from 0.859 to $0.892 \mathrm{~g} \mathrm{~mL}^{-1}$, respectively. The sulfur and nitrogen of crude oil range from 1.9 to $3.0 \mathrm{wt} \%$ and 810 to $1430 \mu \mathrm{g} \mathrm{mL}^{-1}$, respectively. Crude oil also has trace amounts of vanadium from 14 to $50 \mu \mathrm{g} \mathrm{mL}^{-1}$ and nickel $>18 \mu \mathrm{g} \mathrm{mL}^{-1}$. Initial studies were conducted using ultralow sulfur diesel but no elemental sulfur was detected and we utilized these samples for method development.

2.3. SBME. The SBME experimental conditions were optimized using ultralow sulfur diesel with spiked known concentrations of elemental sulfur. The extractions were performed by the following procedure in room temperature: a $20 \mathrm{~mL}$ sample was transferred to the $50 \mathrm{~mL}$ vessel and the stirring bar was placed in it. A $5 \mathrm{~cm}$ of hollow fiber was cut; one end of it was heat sealed and then $200 \mu \mathrm{L}$ of the suitable acceptor phase with triphenylphosphine $(1: 10$ ratio) was placed inside. The open end was blocked with rubber septum. Then, the solvent bar (solvent containing hollow fiber membrane) was placed in the sample (donor phase). Samples were stirred at $73 \mathrm{rad} \mathrm{s}^{-1}(700 \mathrm{rpm} ; 1 \mathrm{rpm}=$ $0.1047 \mathrm{rad} \mathrm{s}^{-1}$ ) for 20 minutes. After the extraction and simultaneous derivatization, the septum was removed and the acceptor solution was withdrawn from the hollow fiber membrane. The membrane was discarded. A $2 \mu \mathrm{L}$ of the extract was injected into the GC/MS.

2.4. Instrumentation. An Agilent GC-MS $6890 \mathrm{~N}$ system equipped with an autosampler 7683B series and a $6890 \mathrm{~B}$ injector was used for the analyses of extracted samples. An Agilent 19091Z-213 column of $30 \mathrm{~m} \times 320 \mu \mathrm{m}$ dimensions, having an HP-1 methyl siloxane stationary phase and film thickness of $1 \mu \mathrm{m}$, was used. High purity helium flowing at a rate of $1.5 \mathrm{~mL} \mathrm{~min}^{-1}$ was employed as the carrier gas. The column temperature program was initially set at $50^{\circ} \mathrm{C}$ and held for $5 \mathrm{~min}$ and then ramped to $150^{\circ} \mathrm{C}$ at a rate of $5^{\circ} \mathrm{C} \mathrm{min}{ }^{-1}$. This was followed immediately by another ramping to $210^{\circ} \mathrm{C}$ at $10^{\circ} \mathrm{C} \mathrm{min}^{-1}$ and held at this temperature for $4 \mathrm{~min}$ to achieve the total run time of $35 \mathrm{~min}$. Auxiliary and ion source temperatures were both set at $280^{\circ} \mathrm{C}$ and $230^{\circ} \mathrm{C}$, respectively. The injector was set in the splitless mode with injection volume of $2 \mu \mathrm{L}$. The total ion current in SCAN mode for ions of masses between 50 and 550 was used for peak identification. Selective ion monitoring (SIM) mode was used for quantification of analytes. The $\mathrm{m} / z$ of 294, 283, 262, 215, and 207 was used for derivatized sulfur (triphenylphosphine sulfide).

\section{Results and Discussion}

The extraction parameters influencing the SBME were optimized (see Figure 1). The peak area was used to determine 


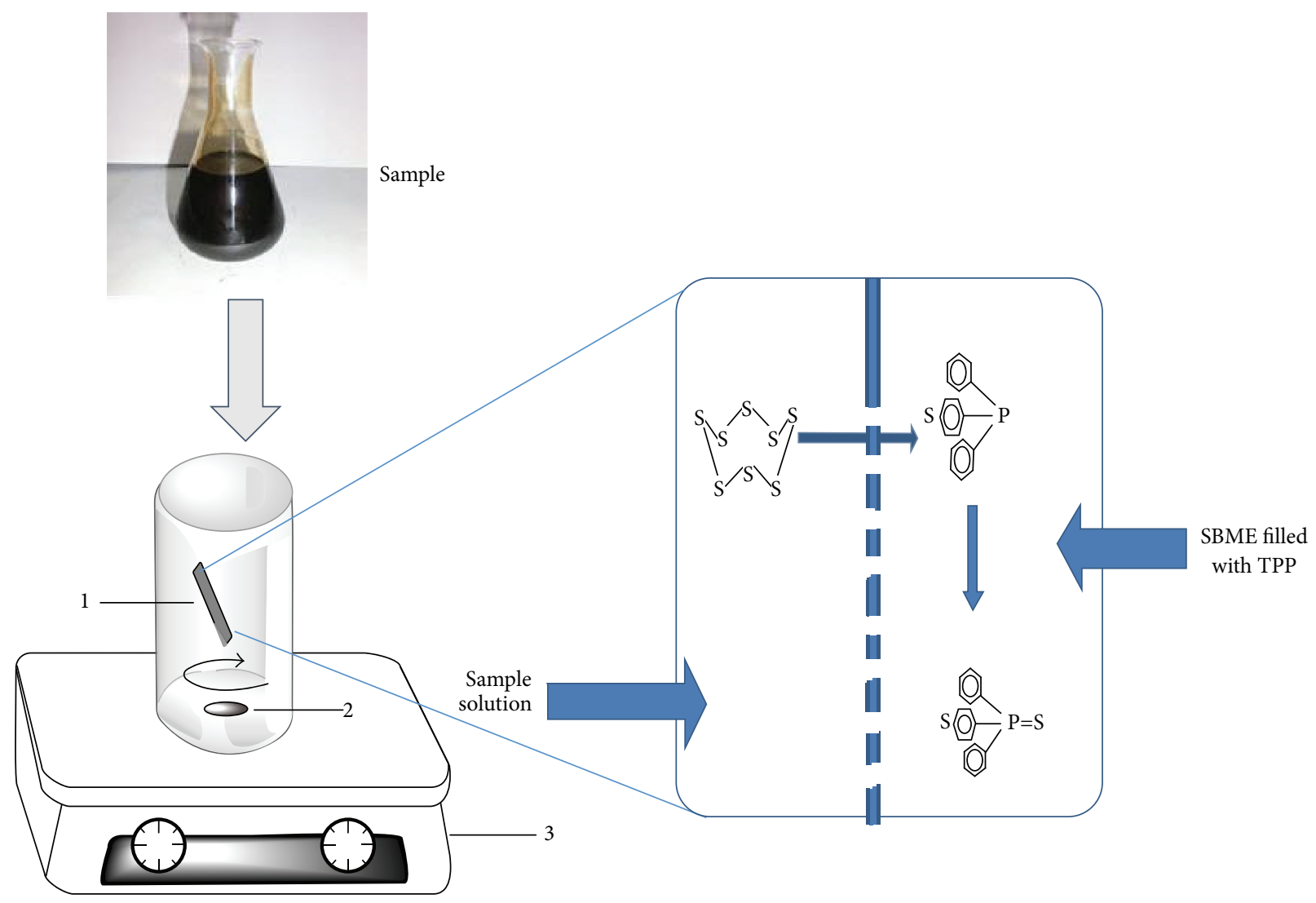

(1) Solvent bar membrane

(2) Magnetic rod

(3) Magnetic stirrer

FIGURE 1: SBME experimental setup.

the extraction performance. Suitable immiscible solvents were selected for the application of SBME. The immiscible solvents stay a long time without leaking from the porous polypropylene membrane and are suitable for the SBME. The triphenylphosphine (10\% wt/v) was dissolved in the same solvent used as simultaneous extraction of elemental sulfur.

The main criteria for selecting the suitable solvents are the solubility of elemental sulfur and triphenylphosphine with low boiling point and the compatibility with the hollow fiber membrane [19]. As a result, acetone, furfural, furfuryl alcohol, and N-methylpyrrolidone were tested. Acetone is slightly soluble in diesel; after a longer extraction time (20 $\mathrm{min}$ ), the volume of acetone was lost due to evaporation. The triphenylphosphine is highly soluble in furfural and furfuryl alcohol, but the solubility of elemental sulfur in these two solvents is lower than that of N-methylpyrrolidone. During the SBME process, N-methylpyrrolidone is more stable even after a $1 \mathrm{hr}$ extraction without loss of solvent volume. The performance of $\mathrm{N}$-methylpyrrolidone shows a relatively higher response than that of other selected solvents (Figure 2).

Pauls (2010) investigated the suitable ratio between elemental sulfur and triphenylphosphine and, based on

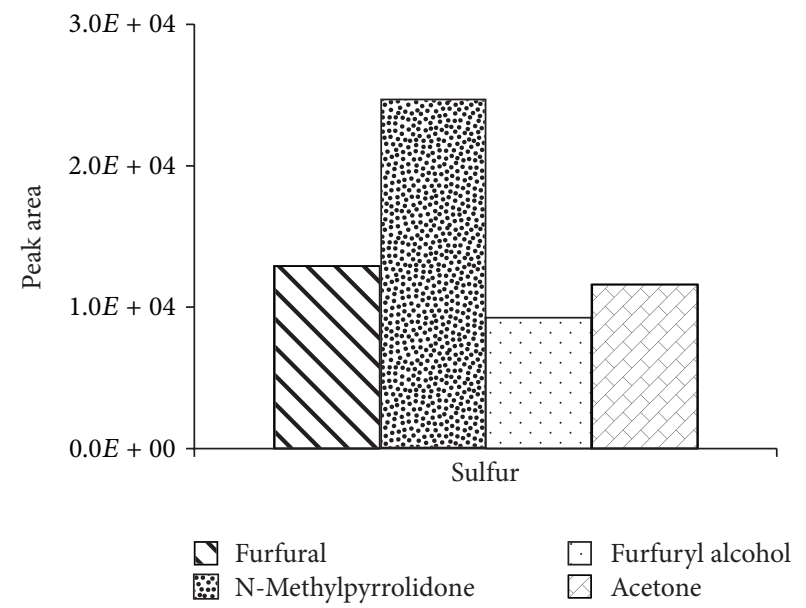

FIGURE 2: Extraction efficiency of different polar organic solvents used for the SBME-GC-MS analyses.

the following equation and experimental study, he demonstrated with

$$
8\left(\mathrm{C}_{6} \mathrm{H}_{5}\right)_{3} \mathrm{P}+\mathrm{S}_{8} \longrightarrow 8\left(\mathrm{C}_{6} \mathrm{H}_{5}\right)_{3}=\mathrm{S}
$$


TABLE 1: Extraction recoveries of elemental sulfur after SBME-GC/MS.

\begin{tabular}{|c|c|c|c|c|c|}
\hline Analyte & $\begin{array}{l}\text { Concentration in } \\
(\mu \mathrm{g} / \mathrm{mL}) \\
\text { Arabian medium } \\
\text { crude }\end{array}$ & $\begin{array}{l}\text { Amount added } \\
(\mu \mathrm{g} / \mathrm{mL})\end{array}$ & $\begin{array}{l}\text { Amount found } \\
\qquad(\mu \mathrm{g} / \mathrm{mL})\end{array}$ & $\%$ RSD & $\% \mathrm{RR}$ \\
\hline \multirow{4}{*}{ Elemental sulfur } & & 5 & 16.07 & 4 & 98.8 \\
\hline & $11.27 \pm 0.43$ & & & & \\
\hline & & 5 & 16.64 & 6 & 101.2 \\
\hline & & 5 & 16.47 & 7 & 98.2 \\
\hline
\end{tabular}

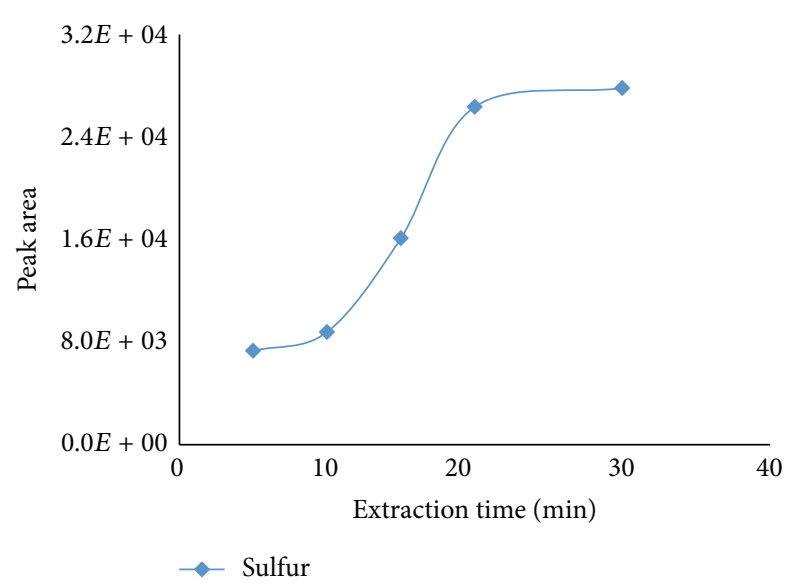

FIGURE 3: Influence of the SBME simultaneous extraction and derivatization time.

that to derivatize $1 \mu \mathrm{g} / \mathrm{g}$ of elemental sulfur requires $9 \mu \mathrm{g} / \mathrm{g}$ of the derivative (triphenylphosphine) [13]. In this study, we use the same ratio of $10 \%$ of triphenylphosphine with extraction solvent.

Various extraction times were set up in extracting the elemental sulfur from the diesel containing a known amount at the stirring speed of $73 \mathrm{rad} \mathrm{s}^{-1}$. Figure 3 shows the profile of extraction time with a peak area after simultaneous extraction and derivatization using SBME. The extraction times of 5 to 60 minutes were evaluated with the SBME. The extraction performance increased with increasing time, but after $20 \mathrm{~min}$ no considerable increment was observed and there was no slow uptake of extraction by the SBME. Therefore, 20 min was selected as the optimum extraction time.

Quantitative performance of the SBME, such as linearity range, reproducibility, limits of detection (LOD), and percentage of relative recoveries were investigated at the optimized conditions. The calibration plots were found to be linear over the range of 1 to $50 \mu \mathrm{g} / \mathrm{mL}$ with the coefficients of determination $\left(R^{2}\right)$ of 9959 . The LOD of elemental sulfur was determined by decreasing the concentrations of elemental sulfur progressively until the signal was just detected at a signal-to-noise ratio of $3(S / N=3)$. The LOD was 0.0511 $\mu \mathrm{g} / \mathrm{mL}$. The interday and intraday repeatability of GC peak areas were investigated for three replicates for a diesel sample.
The percentage relative standard deviations (\%RSDs) of SBME were determined and found to be less than $10 \%$.

\section{Application of the SBME for Diesel and Crude Oil}

Optimum conditions of the SBME were applied to determine the elemental sulfur in the Arabian crude oil samples. Samples were used without dilution and elemental sulfur was detected in all samples (Table 1). A standard addition method was performed to quantitate the concentration of elemental sulfur. After simultaneous extraction and derivatization, a clean extracted chromatogram was obtained. The crude oil samples are highly viscous and prone to interference from sample matrices; the SBME matrix effect was compared with a conventional membrane with the specification of $\mathrm{Q} 3 / 2$ Accurel polypropylene hollow fiber membrane with a $600 \mu \mathrm{m}$ ID, $200 \mu \mathrm{m}$ wall thickness, and $0.2 \mu \mathrm{m}$ wall pore size (from Membrana, Wuppertal, Germany) at the same concentration. As presented in Table 1 , the percentages of relative recovery were observed to be between $75.8 \%$ and $81.3 \%$ for the SBME for thin-walled membrane and between $98.2 \%$ and $101.2 \%$ for thick-walled fiber. Figure 4 shows the comparison of the chromatogram of the SBME with thick- and thinner-walled hollow fiber membrane extraction for the Arabian medium crude oil sample. Results from Table 1 and Figure 4 clearly show that a thick wall membrane has no matrix interference from complex samples when compared to thin-walled porous membrane SBME-GC/MS applications. This could be related to the higher stability of the solvent with more filtration capability of thick-walled hollow fiber membrane.

\section{Conclusions}

For the first time, a solvent bar microextraction method by simultaneous extraction and derivation of elemental sulfur was developed for crude oil samples by using a polar organic solvent. The proposed SBME-GC/MS yields a better sensitivity for the elemental sulfur in the complex petroleum matrices. The current practice (dilution approach) without a clean sample has advantages for clean samples like diesel but for crude oil samples more through cleanup and analyte enrichment is required to avoid interference from sample matrices. The proposed SBME is simple and suitable for 


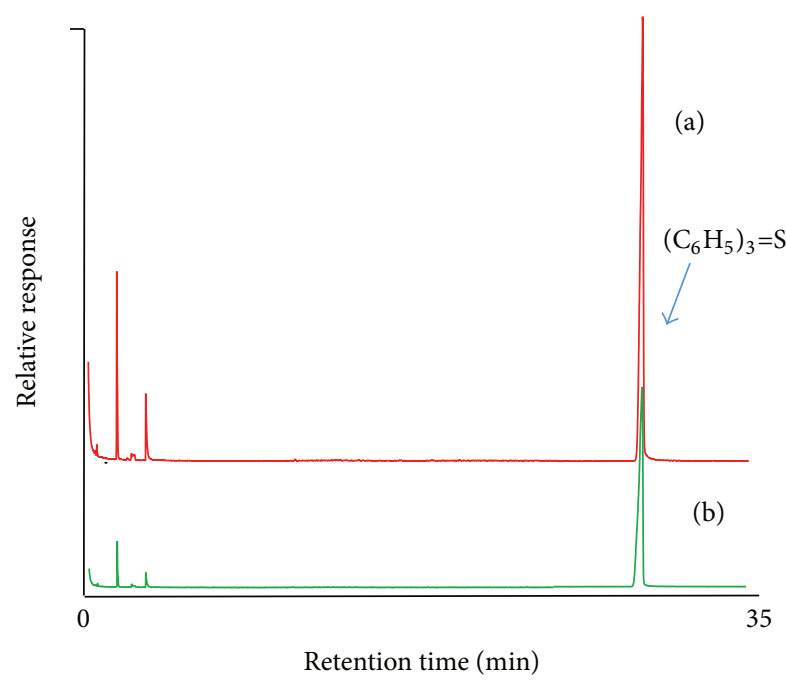

FIGURE 4: SBME extracted chromatograms after (a) Arabian crude oil by thick-walled hollow fiber membrane and (b) Arabian crude oil by conventional hollow fiber membrane (thinner wall thickness).

the direct determination of elemental sulfur in the crude oil without any pretreatment.

\section{Conflict of Interests}

The authors declare that there is no conflict of interests regarding the publication of this paper.

\section{Acknowledgment}

The authors would like to acknowledge the support provided by King Abdulaziz City for Science and Technology (KACST) through the Science and Technology Unit at King Fahd University of Petroleum and Minerals (KFUPM) for funding this work through Project no. 12-PET3009-04 as part of the National Science, Technology, and Innovation Plan.

\section{References}

[1] R. Iwamoto, H. Koshika, N. Takahashi, and K. Inamura, "Formation of free sulfur in hydrodesulfurized gas oil-precautions for pilot test of ultra deep hydrodesulfurization catalysts," Journal of the Japan Petroleum Institute, vol. 48, no. 5, pp. 319323,2005 .

[2] N. F. Nejad, E. Shams, and M. K. Amini, "Ionic liquid-based extraction of sulfur compounds from gasoline as a complementary process to oxidative desulfurization," Petroleum Science and Technology, vol. 32, no. 13, pp. 1537-1544, 2014.

[3] H. Zhao, "Effect of elemental sulfur structure change in light oils on its quantity analysis," Petroleum Science and Technology, vol. 27, no. 13, pp. 1394-1401, 2009.

[4] Y.-W. Chen, H. A. Joly, and N. Belzile, "Determination of elemental sulfur in environmental samples by gas chromatography-mass spectrometry," Chemical Geology, vol. 137, no. 3-4, pp. 195-200, 1997.
[5] H. Zhao, "Effect of elemental sulfur structure change in light oils on its quantity analysis," Petroleum Science and Technology, vol. 27, no. 13, pp. 1394-1401, 2009.

[6] J. K. Barllett and D. A. Skoog, "Colorimetric determination of elemental sulfur in hydrocarbons," Analytical Chemistry, vol. 26, no. 6, pp. 1008-1011, 1954.

[7] C. B. Fliermans and T. D. Brock, "Assay of elemental sulfur in soil," Soil Science, vol. 115, no. 2, pp. 120-122, 1973.

[8] P. F. Henshaw, J. K. Bewtra, and N. Biswas, "Extraction of elemental sulfur from an aqueous suspension for analysis by highperformance liquid chromatography," Analytical Chemistry, vol. 69, no. 15, pp. 3119-3123, 1997.

[9] G. W. Luther III, A. E. Giblin, and R. Varsolona, "Polarographic analysis of sulfur species in marine porewaters," Limnology \& Oceanography, vol. 30, no. 4, pp. 727-736, 1985.

[10] G. A. Cutter and D. J. Velinsky, "Temporal variations of sedimentary sulfur in a Delaware salt marsh," Marine Chemistry, vol. 23, no. 3-4, pp. 311-327, 1988.

[11] D. M. Serafim and N. R. Stradiotto, "Determination of sulfur compounds in gasoline using mercury film electrode by square wave voltammetry," Fuel, vol. 87, no. 7, pp. 1007-1013, 2008.

[12] B. N. Barman, "Determination of elemental sulfur by size-exclusion chromatography optimization and petrochemical applications," Journal of Chromatography A, vol. 740, no. 2, pp. 237-244, 1996.

[13] R. E. Pauls, "Determination of elemental sulfur in gasoline by gas chromatography with on-column injection and flame ionization detection following derivatization with triphenylphosphine," Journal of Chromatographic Science, vol. 48, no. 4, pp. 283-288, 2010.

[14] V. Riis and W. Babel, "Removal of sulfur interfering in the analysis of organochlorines by GC-ECD," Analyst, vol. 124, no. 12, pp. 1771-1773, 1999.

[15] L. Gonsalvesh, S. P. Marinov, M. Stefanova, R. Carleer, and J. Yperman, "Evaluation of elemental sulphur in biodesulphurized low rank coals," Fuel, vol. 90, no. 9, pp. 2923-2930, 2011.

[16] C. Yina, H. Lia, H. Liu et al., "Study on the formation, determination, and removal of elemental sulfur in ultra-low sulfur gas oil," Fuel Processing Technology, vol. 120, pp. 16-21, 2014.

[17] R. Ruiz-Guerrero, C. Vendeuvre, D. Thiébaut, F. Bertoncini, and D. Espinat, "Comparison of comprehensive two-dimensional gas chromatography coupled with sulfur-chemiluminescence detector to standard methods for speciation of sulfur-containing compounds in middle distillates," Journal of Chromatographic Science, vol. 44, no. 9, pp. 566-573, 2006.

[18] V. Toniazzo, C. Mustin, J. M. Portal, B. Humbert, R. Benoit, and R. Erre, "Elemental sulfur at the pyrite surfaces: speciation and quantification," Applied Surface Science, vol. 143, no. 1, pp. 229237, 1999.

[19] I. Al-Zahrani, C. Basheer, and T. Htun, "Application of liquidphase microextraction for the determination of sulfur compounds in crude oil and diesel," Journal of Chromatography A, vol. 1330, pp. 97-102, 2014. 

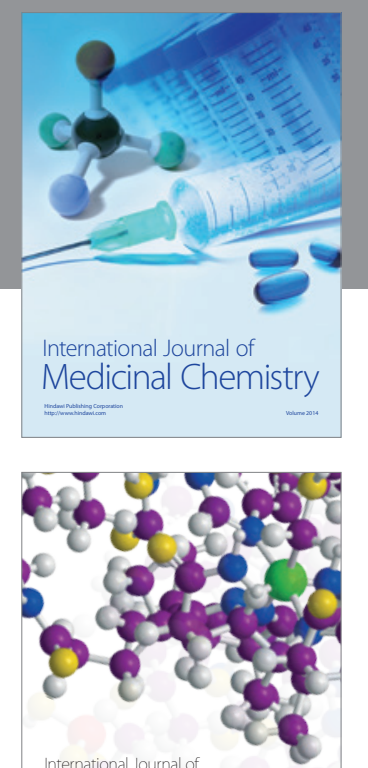

\section{Carbohydrate} Chemistry

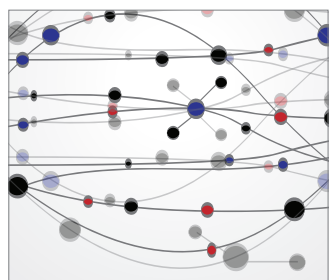

The Scientific World Journal
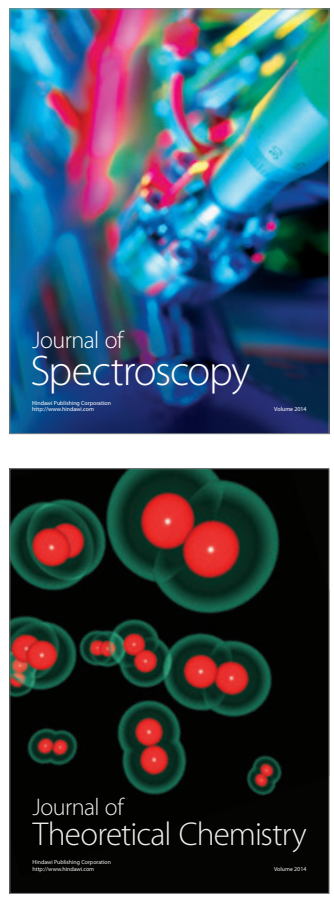
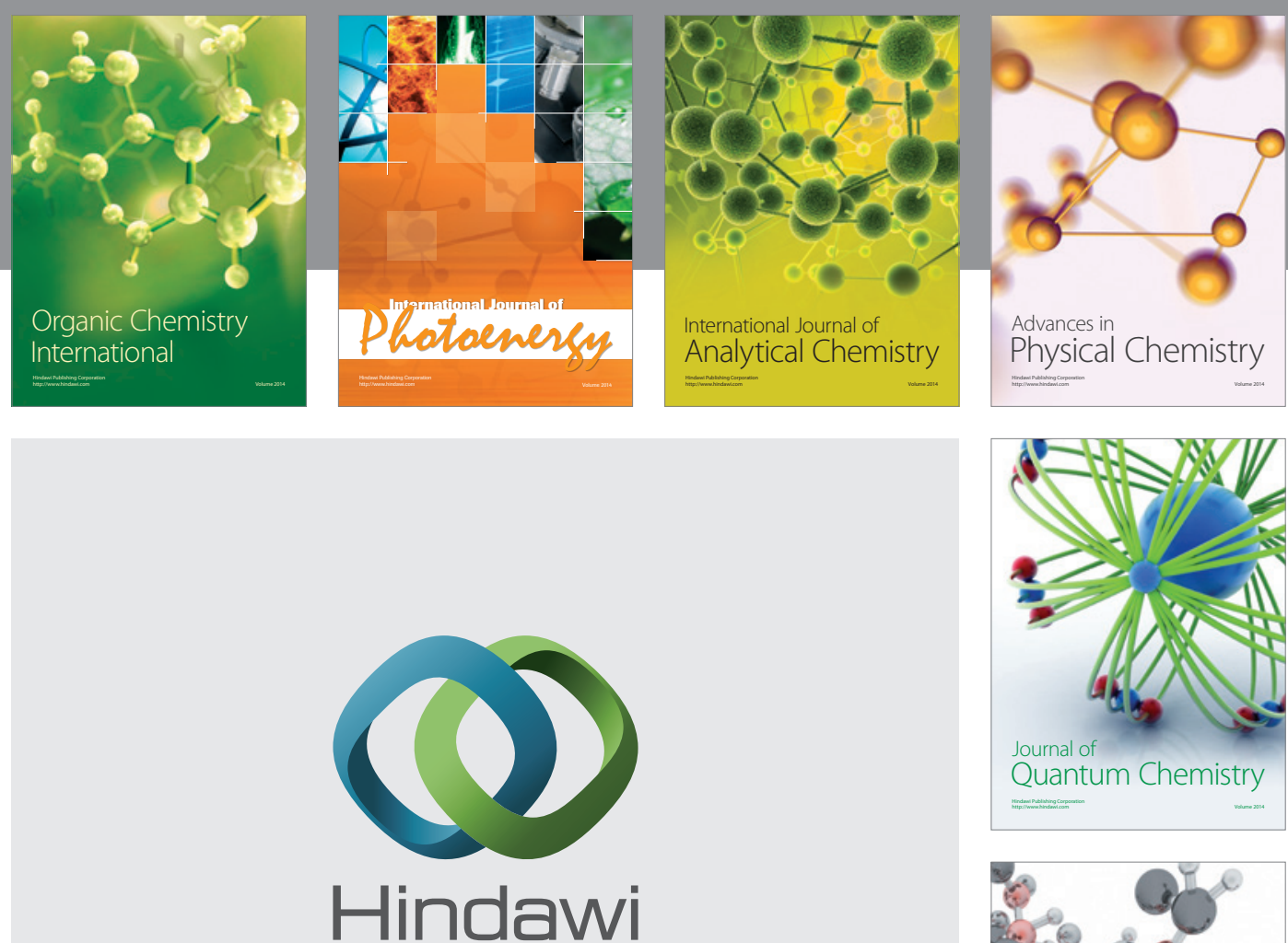

Submit your manuscripts at

http://www.hindawi.com

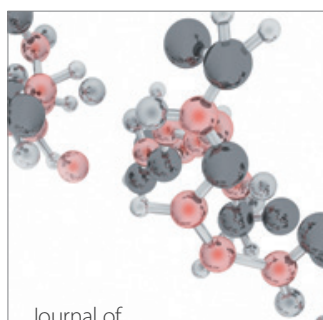

Analytical Methods

in Chemistry

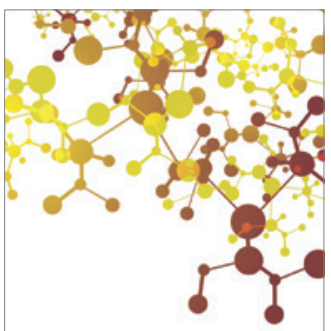

Journal of

Applied Chemistry

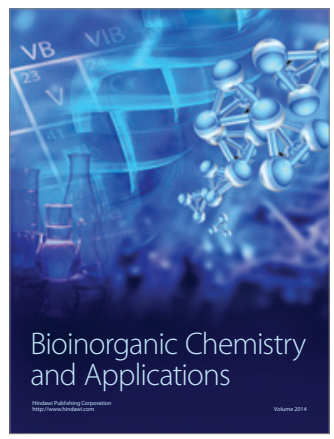

Inorganic Chemistry
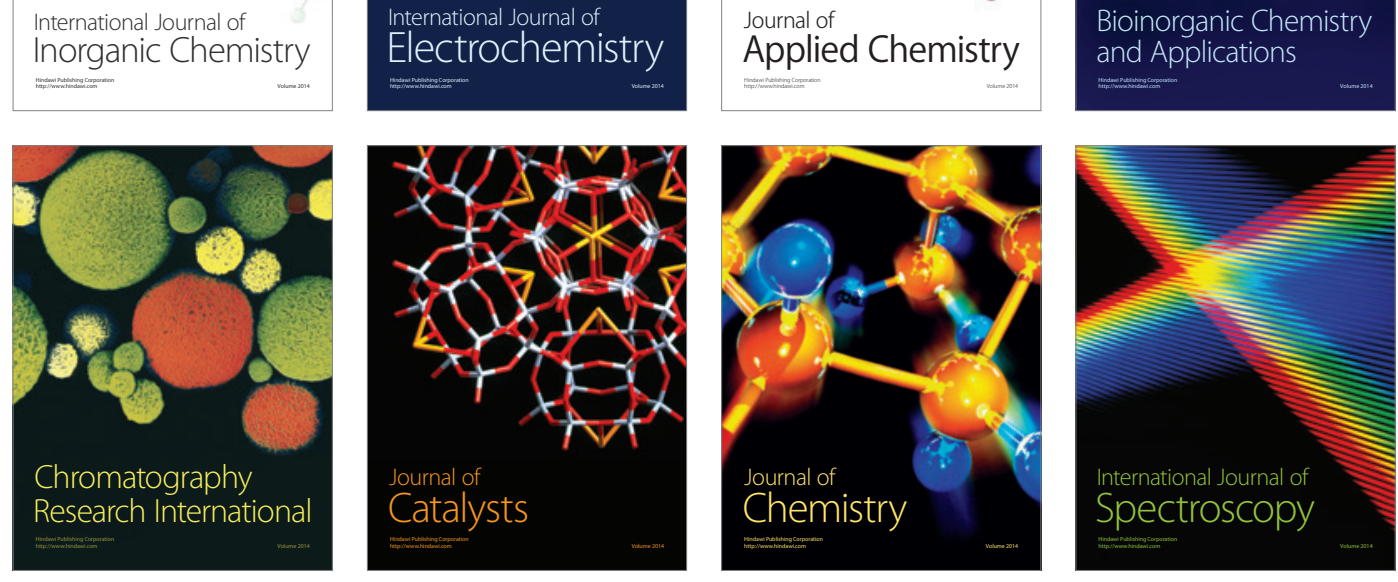